\title{
How the College Students Formation Shapes Group Identity: The Evolution of a Patriotism Production Field
}

\author{
Lingjing Kong \\ Faculty of Humanities and Social Sciences, Beijing University of Technology, \\ No.100, Pingleyuan, Chaoyang District, Beijing, China \\ konglingjing0323@163.com
}

\begin{abstract}
In July 2019, tens of thousands of students and teachers from universities in Beijing participated in the 70th anniversary of the founding of the People's Republic of China as a part of civilian parade. This article intended to use a sociological perspective to observe and record a series of phenomena that took place during the training process in more than two months, as well as the changes in the behaviors, attitudes, mental states and subjective experiences of several participants including me. Because of the force majeure of the event itself, the author as a participant directly intervened in the situation without any priori values and assumptions, and conducted continuous participant observation as a member of the celebration event. Based on the relevant fieldwork data, this article is intended to explore a series of transformations of the queue from the perspective of static structures and evolutionary processes. On this basis, this article will attempt to construct theoretical models about the evolution of the college students formation and inclusive theme-focused education activities respectively.
\end{abstract}

Keywords: Patriotism; Group Identity; Collective Consciousness; Group Psychology.

\section{College Students Formation during Military Training Period}

As the first stage of this event, the period that unifies the general military education and training in China (Chinese: 军 训) and the march-past training can be defined as the Military Training Period, which was the first time that thousands of students and teachers took the stage as a group. It can be hardly call the formation during this period a solidary group, because widespread negativity permeates the words and actions of participants, speaking of exertion, heat, sunburn, deprived holiday lives, and even the irrationality of the whole event. According to Durkheim 's definition of social solidarity, the formation of the Military Training Period can be defined as a secondary group of negative solidarity[1], which the social bonds that bind the group together are not a strong and homogeneous collective consciousness or interdependence based on heterogeneity, but rather external coercive discipline, uncertainty about rewards and punishments mechanism, and the gradually increased sunk costs.

During the military training period, the most frequent topic of conversation among individuals at their leisure was the rewards and punishments mechanism for the event. Speculation about the amount of the remuneration spread through the social network of the formation, but no one could come to a definite conclusion, only to draw a general range from the legends left behind ten years ago, the words of the counselors and the analyses of their peers. These naturally failed to make an economically rational value judgement between withdrawing from the activity to enjoy the summer holidays and the unknown rewards, thus making a perfect choice. On the other hand, the effectiveness of the punishment mechanism likewise varies from person to person. Many people who thought it was a highly compulsory political mission at the beginning of the event found a small group of students who, for a variety of reasons, only participated in the annual general training during the subsequent process and thus doubted the coerciveness of the mission itself. Withdrawal from a political task with coerciveness inevitably entails certain penalties, and different types of individuals are afraid of their potential penalties. In order to explore the effect of reward and punishment mechanism on individual behavior, an interview has been structured with students in different grade ranges and political statuses to find out that both students with high academic achieving and poor academic performance were more concerned with grade in this celebration event of civilian parade, while students who were activists of party application and those who were interested in joining the party saw it as an opportunity to improve their partisan (Chinese: 党 性) and awareness, or as a mandatory political task that they had no choice but to take part in, therefore could not undergo the punishment that came with quitting. It is known that at least two teachers from $\mathbf{J}$ college who were involved in the political censorship told students that they would have faced a series of regrets if they had failed to attend the celebration, these regrets were interpreted as an implication of grades or some soft criteria by students. Of course, there are also a few individuals who engage in deviant behavior in the face of uncertain rewards and punishments mechanism.

From the perspective of individual action, the sunk cost also becomes an important factor in maintaining group cohesion during the military training period. A few individuals who showed evident negative emotions during this period have been interviewed, which aimed at exploring the contradiction between their rebellious emotional attitudes and compliance behavior. Interviewees generally felt that they had put a great deal of time and effort into this activity and that withdrawing at this point would undo all their efforts. This narrative was found increased in proportion as the military training drew to 
a close, and the attitudes implied became more assertive. In the case of the formation: trapped in a negative solidarity social group sustained by coercive disciplines and economic rationality, it is impossible to acknowledge that the sunk costs of the past are meaningless, otherwise the previous training and investment would have been wasted and it would be better to persevere until the end. In this case, the sunk cost became an invisible bond of the formation, to the extent that some individuals gave new meaning to this sacrifice.

In Durkheim's perspective, members of the Mechanic Solidarity group not only share similar beliefs, values and moral standards, but their motivations are often strikingly homogeneous[2]. By interviewing the group, the analysis of the early stage of the formation could provide a glimpse into the characteristics of this group.

- Question: "Why did you want to take part in this celebration event in the first place?"

- Postgraduate W: "The answer is obvious, this opportunity may never come around twice in a lifetime. I took part in this event while my supervisor strongly objected to it, he thought it would affect the progress of my research."

- Postgraduate M: "It's quite rare to see this kind of opportunity, so it's beneficial to have some insight afterwards."

- Undergraduate Z: "I have nothing else to do in the summer holiday anyway, otherwise I'll just play games."

- Roommate Z: "I thought it was compulsory to take part."

- Roommate P: "My parents have to force me to go, I'm reluctant."

- Friend L: "The school forced me to join, and I'm forbidden to quit. The teacher urged me to participate with the stick and the carrot, and I am afraid of being made trouble of."

- Friend Y: "I can encounter Chairman Xi!"

As can be seen, different individuals participate in the activity for different purposes, not to mention collective consciousness. According to Weber's social action theory, the actions of the individuals within the formation during the military training period can barely be considered as traditional social actions, which are carried out through habit, i.e. group inertia and coercion. The definition of the formation as a group of negative solidarity is also attributed to the passive resistance that prevails in the interaction between the individuals and the organizer during the military training period: pretending to be sick in order to get a break, behaving languorously after the assembly of instructors, deliberately lowering the voice of the army slogans, etc. There was even a blatant confrontation with authority during the first half of the military training period. At first, students from the third squadron stood up and loudly challenged the instructor's decision, and then several students from the $\mathrm{S}$ college applauded the unreasonable aspects of the speech made by the head instructor. James Scott has described such actions as everyday resistance: these scenes are often insignificant blips in public discourse, or even do not record at all in the official narrative[3]. For the individual, these actions are unorganized but unspoken, self-indulgent resistance. Such resistance is a practice of the individual's search for a sense of loss of control in the context of recognizing the power of authority, and can be seen as a form of guerrilla tactics and partial victory at the micro level[4].
The widespread occurrence of negative resistance makes it easy to see that the power relations and order of the formation during the military training period were based on conceivable pretense.

\section{Identity Construction of the Formation}

Different from general military education and training, the civilian parade of 70th anniversary celebration is charged with political mission, so that the formation is assembled by head of school, party branch and the military together. Organizers from the party branch and the military have set up a headquarter to coordinate the overall situation and to take charge of planning. Specific to responsible for each battalion which includes students of one college, that is, Subheadquarter (Chinese: 分指). It is obvious that the authority as the school and sub-headquarter which based on coercive power with an uncertain mechanism of rewards and punishments cannot bear the responsibility. Under such a premise, the authority carried out a series of activities that seemed to have nothing to do with the training itself, while it started the remold plan of the formation. The primary task is to establish an individual's identification with different levels of identity groups through a series of fun activities as attribution guidance. Specifically, through competition and cooperative social interaction, the authority builds students' identity for the squadron, battalion and even the whole formation that represents our school. During the military training period, there was an absorbing phenomenon that when participants were engaged in fun activities such as singing, playing games and even interacting with instructors, the excited and joyful mood of the students was in sharp contrast to the lethality of the training. Military training itself can be seen as a series of grueling and exhausting activities, and the militarized management model of patriarchy aggravates the resentment that individuals have no place to relieve. In this case, under the guidance of the authority and instructors, participants cooperated to compete with other squadrons and battalions by a series of interesting activities, venting their negative emotions through competitive social interaction, and also building a sense of belonging to their own group through cooperation. Just as the psychoanalytic theory states: deep in the core of our emotional experience lies the essential need for the construction of illusion[5]. The multiple and fragmentary negative emotions in life need to be guided to a unified outsider illusion, it seems that all the dissatisfaction and disaster can be attributed to this object; while individuals also tend to rely on an insider illusion, attributing to it joys that do not belong to it.

Each kind of identity is based on specific discrepant fundamentals which constitute the boundary of identity group, that delimits the group-self boundary for us. People often build a concentric circle of loyalty or belonging on the basis of a specific discrepant fundamental[6]. The group identity closer to the inner circle can mobilize intense perceptive symbols that are closer to an individual's life, and then endow it with a strong emotional connection. For the group identity of formation constructed by external forces to serve the civilian parade, its construction sequence must be a process 
from the inner circle to the outer circle. Specific to the formation, the competition which results in competitors and a series of rewards and punishments related to prestige and respect become the boundaries between insider and outsider, and the individual's dissatisfaction with the authority and the celebration event itself is transferred to the imaginary virtual image of outsider. As far as my personal experience is concerned, the fourth squadron in which the author was subordinated has achieved a brilliant record in the party history competition, and the seventh battalion has repeatedly won the singing contest. Even the formation that represents our school was also praised by headquarter for walking orderly in the simulation rehearsal of parade. The process and results of these competitions carried out by groups constitute the common experience, memory and emotion of the corresponding identity groups, and become a strong relationship to maintain group solidarity.

On this basis, the effect of carrying out theme-focused education is self-evident. In my squadron, a series of activities such as watching patriotic movies, holding revolutionary reading salons and writing essays for the 70th anniversary of the founding of the People's Republic of China. Although most of the Chinese students would not take the initiative to accept the ideological and political education (Chinese: 思政 教育) in normal life, they have a very positive attitude towards the republic, which has been developing just like the soaring phoenix and the rising dragon under the guidance of performance legitimacy. Theme-focused education further clarified and deepened the patriotism of individuals, and as the personal participants of the celebration, this simple patriotism can easily develop into a collective sense of identity and honor. In my opinion, the official patriotism constructed from top to bottom in authoritarian countries operates on the basis of "Integrated Concept of Country" which contains nation-state, government, political party, nationality, culture, etc. With the current regime as the object of emotional projection, the regime itself obtains ruling dividends with the help of homecountry isomorphism, which transferred people's simple feelings of family toward political tendency. This also means that the existing patriotic feelings can slide along and be assigned to different levels of identity groups associated with patriotism. Together, these feelings form a strong collective consciousness, as emphasized by Durkheim, form the basis of group order and maintain connections among members. Individuals began to see their group members as fellow patriots, so that a strong sense of community was fostered and will be further deepened and strengthened in the following activities.

As the role of a teacher itself, the counsellor also played an indispensable part in the evolutionary process of the formation. As judges in the military training period, teachers and instructors often had a strong collective consciousness and punished students with the repressive characteristics of the legal system.

- A student in the first squadron in violation of discipline by removing the hat lead the consequence that the entire seventh battalion got punishment of standing at military posture.

- The seventh battalion didn't gather on time, their instructors was punished to do push-ups.

- "You represent the whole collective", which is often emphasized by the seventh battalion leader in his lecture.

- If one student is slow/wrong, all will be punished.

- Student Z applied for leave to the counselor because of family matters. The counselor emphasized the native land emotion, saying, "we are making contributions to the country, and we should put the country first."

- The students wearing armbands in the headquarters neglected their duties (playing mobile phones on the post), and were reprimanded by the head counselor for two hours. They were characterized as immature people lacking collective consciousness and sense of responsibility.

It is not difficult to see that teachers and instructors regard all acts that violate and damage collective consciousness as "crimes" in the judicial process. In Durkheim's view, the typology of legal and judicial mechanisms can reflect the type of solidarity of a social group. In the pre-modern society of mechanical solidarity, criminal acts subjected to punitive justice were defined as specific actions that violated the collective consciousness: actions that were viewed not as an offense to certain individuals, but as threats to the collective consciousness of the group. On this basis, sanctions for evil acts can activate collective consciousness and thus maintain social cohesion[7]. By observing the judicial pattern during the military training period, punitive justice could not only activate, but also shape the common consciousness through the guidance of attribution to a certain extent. Although the formation during this period is not enough to define as a group of mechanical solidarity, the judges deliberately defined the behavior of the deviant as a violation of the collective, and fixed this perception through collective punishment. This kind of punishment with strong emotional factors has gradually become an expression of collective passion. The purpose of punishment is not to make the deviant abide by rules and regulations, but to heal the damage caused by deviant behavior to the collective consciousness. To sum up: both the rewards mechanism and the appropriation of existing patriotic feelings at the macro level and the attribution guidance through punitive justice at the individual level are essentially the efforts of the authority to shape identity groups and their emotional bonds

\section{Situational Definition of the Social Network}

In the process of unstructured interviews with some individuals, an interesting phenomenon can be observed: in the same revolutionary song training activity, as soon as the prelude starts, the $\mathrm{J}$ college where the author used to stay often began to chorus in a passionate and full voice. On the contrary, the situation in the $\mathrm{S}$ college is completely the opposite. Many students adopted a passive attitude of resistance and remained silent during the whole process, and the effect of the activity is relatively poor. $\mathrm{W}$ college was conventional: the students completed the revolutionary song training with a normal tone and attitude. Through follow-up observation and interviews, it is found that $\mathrm{J}$ college has a large number of patriotic activists: they are usually the pacemen of all kinds of student organizations and political activities, and are defined as models with high awareness in the school. These activists can 
be defined as the vanguard of the new era, because they play a crucial vanguard role in the evolution of the whole formation. Afterwards, an interview has been conducted with students of $\mathrm{J}$ college.

- Question: "To take this as an example, we are always sing 'socialism is good, communism is good'. What do you think is socialism and communism?"

- Classmate N: "I am not quite clear, it should be kind of serving for the people, establish a pantisocracy?"

- Question: "Do you enjoy this kind of activity?"

- Student N: “Actually, I don't quite like it. It's just a cheering feeling when we sing together. "

From the perspective of political sociology, post-reform China is politicized as a period of de-politicization because of its loss of revolutionary consensus and idolization of communism's politicization: to be specific, the regime characterized its core connotation as order, stability, loyalty and development. In this period, the regime has put the narrative of development as priority, and sees Marxism as a powerful tool for the rejuvenation and enrichment of the Chinese nation. While the narrative of revolution, whose core connotation is progress and change, intended to mobilize the proletariat and thus create a worldwide union of free men, was put in a secondary order. It is not hard to find from the above interviews that individuals can hardly feel the revolutionary ideals and passions that have been sown in the hearts of generations in ideological education, but are captured by the atmosphere driven by the activists in the formation. After the reform and opening-up, the Chinese Communist Party was transformed from a Leninist vanguard party leading the revolution into a 90-million-member national party that aims to recruit social elites and achieve national rejuvenation. This also means that the Party is more interested in absorbing social elites who can help achieve economic development and national prosperity. The awareness (Chinese: 觉悟) mentioned above is naturally defined as loyalty and dedication to the country and the central committee of CCP.

During the second training, it was often the activists with high awareness who started the training activities and raised the atmosphere to just the right degree. As mentioned above, the activists with both ability and awareness are already the popular central figures in the college, with a rather complex and powerful social network. Led by those activists, other students also gradually joined in the joyful activity like the singing contest, and formed a good interaction with each other: some students often make exaggerated facial expressions, adding a carnival atmosphere to the whole activity with a funny and friendly gesture. It is not difficult to draw a conclusion that the positive attitude of $\mathrm{J}$ college students when singing revolutionary songs is not because they have a deep understanding of the socialist history and communist ethics described by the activity itself, but because the activists as leaders have endowed the revolution songs with a positive social significance. As Goffman describes, the situational definition means that when the elite constructs this positive social atmosphere, other individuals also have to act in a planned way, representing themselves in a predetermined way in order to impress others. This is known as impression management: by using words, gestures and singing to make others form the impression we need to have "good relationships"[8]. On this basis, the content of revolutionary songs itself is gradually accepted by individuals within the symbol system of social network, thus transforming into spontaneous simple patriotic feelings of individuals, realizing another leap of group cohesion.

In conclusion, under the combined action of top-down identity construction by the authority and social network influenced by activists, the formation has broken away from the negative solidarity based on economic rationality and coercive force at the end of the military training period, while most of the individuals involved are anchored to different levels of common emotion, setting the stage for subsequent training.

\section{Analysis of Two Cases of Deviant Behavior}

Despite the efforts of the authority and activists, the formation has appeared the collective consciousness of belonging and the cohesion brought by it, but it is still inevitable to have deviant behaviors in the process of evolution. Two examples that the author has personally contacted and participated in are set up to elaborate and analyze.

- Example 1: W has been complaining constantly since the beginning of the event, saying that he did not want to participate in the military training and the subsequent celebration. He is said to have been forced to participate from the very beginning, and thinks that the themefocused education is "puffery" and very formalistic. He believed that patriotism should be a simple feeling of spontaneity, not something that is forced upon one under authority. W was also worried that quitting would affect his GPA and even facing a series of unexpected difficulties. But his reluctance to take part in such events overcame his concerns and he eventually backed out of the celebration event with the help of other friends.

- Example 2: $\mathrm{K}$ had doubts about the military training after learning about the existence of general training students. He had no objection to the exercise itself, but wanted to devote the time to something he thought was more meaningful for himself. "For me, there's nothing bad about being part of this training," he said. "It's a once-ina-lifetime opportunity. But as far as the activity itself is concerned, I don't think it has any practical effect on people and civic issues, nor does it contribute constructively to me, so I'm going to work part-time or learn how to drive." Later, $\mathrm{K}$ applied to the counselor to withdraw from the event on the grounds of physical illness, but the counselor intentionally or unintentionally suggested that participation in the activity would be directly related to a series of grades. $\mathrm{K}$ attached great importance to GPA and his family's advice, eventually, he participated in the 70th anniversary celebration in its entirety.

Nominally, the celebration is a political mission that requires participation and cannot be withdrawn, so these two examples are the deviant behaviors that violate group norms. According to Merton's theory of deviance, deviant behaviors can be divided into five categories in accordance with the cultural goals and institutionalized methods of the deviant. W replaced the cultural goal of accomplishing political tasks and 
celebrating the birth of his country with the goal of enjoying his summer vacation. He also replaced the institutionalized methods of obedience with the methods of escape, It can be defined as Rebellion; K questioned the rationality of the whole event and gave up the cultural goal, but had to obey and participate in the training to follow the institutionalized methods, which is Ritualism[9].

It can also explain these deviant behaviors in terms of social control. In the transition period of the formation, the means of social control are still dominated by discipline, supplemented by morality and group consciousness. The problem lies in that the discipline is not the same as the law guaranteed and enforced by the state power. Instead, it ensures its binding and mandatory nature by imposing sanctions on members' status, reputation, membership and even some actual interests in the group. For individuals, it fails to go beyond the scope of economic rational choice. Through the analysis of the above examples, $\mathrm{W}$ and $\mathrm{K}$ were found indifferent to the membership of the group at all, not to mention their status and reputation in the group. And the actual benefits that the school and the counselor have in their hands are not even enough to sanction W: he doesn't care about the GPA in this one credit. From an Institutionalist perspective of cultural background and emotional bond, $\mathrm{W}$ and $\mathrm{K}$ questioned the significance of the event itself, and their value judgment is inconsistent with the values of the authority. The two sides have different judgment standards of good and evil, naturally can not count on the moral standards of the school to make the two deviants even a trace of guilt and sense of moral betrayal. Thus, it is not hard to see that although the authority and activists construct the common emotions of the formation in terms of group identity and social context definition respectively, there were heterogeneous individuals that could not be internalized into the group value from the beginning, which laid hidden dangers for the continuous deviant behaviors occurring later. For a few members of the group, their actions on the celebration never get out of the realm of economic rationality and into the realm of cultural value.

\section{The Rehearsal Period: The Production Field of Patriotism}

Corresponding to the military training period, the training tasks that followed the end of the institutionalized military training process could be defined as the rehearsal period. If the actions of the authority during the military training period are subliminally altering the cohesion of the entire formation, the first Tiananmen rehearsal, as a crucial point, completely makes the formation undergo a qualitative change.

- Record: The first rehearsal exaggerated and highlighted the two dominant subjective experiences of group members during this period: tiredness and excitement. After boarding the train at around 6pm, after a bumpy, long journey, members arrived on Chang 'an Avenue, where they had to wait for up to three hours. The students generally leaned against the wall, sat on the fence pier, or even lay down on the ground and fell asleep. There are also many students who complained that their normal work and rest have been disturbed, worried about endocrine disorders so that their health might have been affected. But as the PLA marched in unitary procession down Chang 'an Avenue, and military equipment drove past with a mixture of noise and smoke, much of the students' fatigue turned to excitement. For a while, the girls were talking about the firm eyes and neat steps of the soldiers, calling them the "Chinese NO.1 Idol Group" while the boys were either admiring the valiant posture of the female soldiers, or speculating about the mysterious weapons hidden by the curtain. But when the military formations actually set foot on Chang 'an Avenue, everything changed. As far as the eye could see, thousands of spectators, huge portraits of political leaders, and trumpets leading the passionate military music created a formidable atmosphere that changed the attitude of all participants. The students spontaneously raised the flowers and cheered heartily. The audience actively interacted with other formations, as if the previous exhaustion had been swept away. At the moment of walking through Tiananmen, "Bless the motherland, long live the motherland", the voice shook the earth, resounded throughout the world.

What has changed is not only the subjective experience of individuals, but also people's attitude towards activity itself. After the first Chang 'an Avenue rehearsal, students expressed their excited feelings in WeChat Moments, some texts were deliberately selected and recorded.

- Classmate L: "Too shocked!! I felt more and more that I loved my country."

- Classmate D: "Huge value of a night, too handsome!!"

- Classmate Y: "Bless the motherland, long live the motherland. (emoji of national flag) I burst into tears, and I even willing to be reborn to China in the afterlife."

- Student H: "I stayed at night in the streets of Wangfujing, ran in Chang 'an Avenue. It's the highlight moment for all of us, and my eyes were full of tears."

It is not difficult to find that the formation at the rehearsal period has already formed a strong collective consciousness: members have a clear and strong sense of belonging and responsibility to the group. In a sense, since the military instructor team left with the end of the military training period, the school has largely parted with its despotic power and coercive force over the formation group. When focusing on the group in the late rehearsal period, it can be illustrated that most individuals spontaneously participated in various related activities organized by the school, and in the process, they showed a highly similar value goal of celebrating the birthday of the motherland, held the same moral evaluation standard and presented a highly consistent emotional experience. The organization itself also reflects the characteristics of noninstitutionalized interaction and emotional relationships, such as spontaneous discussion and emotional communication. It can be said that the formation has successfully evolved from a secondary group of negative solidarity into a primary social group of mechanical solidarity.

At its most essential, the rehearsal scene itself can be defined as a web of meaning woven by specific symbols of patriotism. A great number of media have attributed China's lavish and grandiose events to the grand narrative that was propagandized by the official. This character also makes 
Chinese people's feelings of affection and love for something rarely come from small personal emotional touches, but need to be conveyed by a larger sense of collective honor.

From the perspective of Lacanian psychoanalysis theory, the essence of grand narrative is the weaving of meaning web, which produces completely different illusions and meanings through the complex interactive network between symbols. The atmosphere created by the grand scene, collective action and sound, light and smell of the mass parade has great impact and emotional appeal. The positive emotional experience inspired by these symbols is anchored in a specific narrative of scenes: the martyrs who sacrificed their lives to fight against foreign enemies; scientific research workers who have worked assiduously and incognito for the construction of the motherland for the past 70 years; the glorious history of the motherland, which started from scratch, endured humiliation and developed rapidly until it took off. As long as the individual understands a little bit of it, one will spontaneously place oneself in a time and space that spans a hundred years, not to mention the complex emotions felt by all of his peers through the ages.

To better understand how the web of symbolic meanings interacts, we'd better focus on "the empty car with the number plate 1949" that appeared at the parade. Objectively, it is just an expensive and delicate empty car, but it is endowed with the significance of the souls of countless martyrs who laid down the new China by fighting with their blood and lives. Human actions to an object are mainly based on the meaning they give to it[10]. The audience in front of the screen is moved by the empty car because they accept the meaning that mass media has attached to it. Even the formation of the civilian parade was a symbol endowed with meaning by the public. Dozens of formations happily passing Tiananmen square in turn act as a series of signifiers, referring to all the joy experienced since the founding of the People's Republic of China. The web of meaning conveys abstract sensuous symbols in a concrete and palpable way, thus mobilizing strong emotional responses. If we carefully observe the paradigm of military parades in authoritarian countries, it is not difficult to find similar symbols abound in every corner of the activity, and the meaning brought by them will be spontaneously developed and spread by people. The strong emotion aroused on this basis is enough to bring tears to one's eyes, and becomes a powerful force to maintain the cohesion of the formation.

The web of meaning constructed by symbols does enable the individuals involved to obtain the authentic experience of patriotism and heartfelt moving, but it depends on spontaneous emotional transmission after all, and cannot guarantee that everyone can obtain such a degree of emotion. Therefore, individuals not captured by the web of meaning should be the object of my research.

The individuals who strongly opposed or disliked the event during the military training period, but who expressed patriotic feelings during the rehearsal period were interviewed. They said they were genuinely moved, but not as strongly as the contents in WeChat Moments suggested. However, in the current environment and public atmosphere, it is fashionable and gregarious to express patriotic feelings. Just as the group psychological effect described by Le Bon, when the vast majority of individuals in a group agree with a certain emotion or consensus, then the emotion becomes infiltrating as it spreads in the social network[11]. In other words, the individuals mentioned above only make the "correct" emotional reflection required by the stereotypical situation which can be seen as customary group consensus. Specific individuals acted in this way not to identify with the common emotional or cultural environment of the formation, but to better integrate into the group and maintain the hard-won sense of belonging. On this basis, they tend to converge on the mass values of the group, because deviating from the group cognition and existence is likely to be excluded by the other people in this group. Group psychological effects make the collective emotion more widely spread, so that every individual in the formation is affected by it.

The symbolic meaning web of the rehearsal scene creates a collective consensus for individuals, while the group psychological effects of the social network spread it further. Due to the disruption of their daily routines, participants' fatigue and poor subjective experience were paid close attention in this process, and the method they chose to overcome these feelings. Strong feelings of patriotism, though they are real, cannot completely dispel physical fatigue and anger at the usurpation of rest time. In this regard, some individuals who had delayed important personal events due to training were interviewed.

- Question: "Do you feel tired? It looks like this training has messed up your part-time schedule. What do you think?"

- Student Q: "It does conflict, but we can't do anything. I think participating in such kind of celebration is much more meaningful than taking a part-time job."

- Classmate W: "I am very tired, but the opportunity to sleep on Chang 'an Avenue may also be this once in life, ha ha ha..."

It is not difficult to find that the interviewees do care about their subjective feelings and the part-time jobs they have missed. At the same time, however, they attached equal or even greater significance to the range of physical and experiential losses caused by the celebration event. When it comes to explaining the emotional experience of the individual at the micro level, it is effective to apply Lacanian psychoanalysis: even without discipline and guidance, people seemed to spontaneously seek some higher meaning and value beyond their basic physiological needs.

- "When horrible happens, our spontaneous tendency is to search for meaning. It must mean something. You know, like AIDS, is was a trauma. Then, Conservationist said it's the punishment to our sinful way of life, and so on. Even if we interpret the catastrophe as a punishment, it makes it easier in this way. Because we know it not just some terrified blind force, it has the meaning. It's better to feel that the god punish you then to feel that just happened. The disaster itself has no meaning, and all these explanations are attempts to symbolize it. The Real is meaningless and absurd, while meaning can only be found in the Symbolic and the Imaginary"[12]. 
The first step in constructing a meaningful universe, as Zizek argues, is to symbolize an invasion from the Real, such as to regard the sudden emergence of AIDS as a "punishment". Then came the power of the Imaginary: it interprets AIDS as a divine punishment and gave it meanings beyond human's life, such as a more pious and humble way of living may make people escape from this kind of disaster. To sum up: when disasters and losses occur, individuals will spontaneously initiate a process of rationalization and symbolization[13], so that losses can be transformed into positive meanings to some extent. Unwilling to acknowledge the vested losses and its accompanying emotional damage, people have to empathize with the story or concept woven by symbolic order. This is an inappropriate example of the event itself, because the celebration is not meaningless, like sickness and disaster, but rather beneficial to most people, and many individuals genuinely enjoy it. It only be discussed at a micro level how individuals can use the mechanics of the functioning of the Imaginary to smoothen out the insignificant negative emotions that come with the celebration.

At the end of the event, an extremely interesting individual phenomenon could be observed. L retained strong negative feelings from the beginning to the end of the event, not only because he had relatively independent and firm value judgments and political stances, but also the training for the celebrations had seriously disrupted his plans and had had a considerable impact on his life. However, on the last day of the celebrations, when he saw the float (decorated vehicle in parade) carrying the veterans slowly passing by and waving to the celebrating crowd, L could not help bursting into tears and thus changed his emotional attitude towards the formation after the event. It is indeed impossible to ignore the fact that neither the common emotional construction of the authority, the situational definition of the activists nor the symbolic web of the rehearsal scenes allowed them to change their emotional attitude towards the whole event. If we want to explain what is happening to $\mathrm{L}$, we might as well introduce a structuralist explanation of symbols: the overlap and slide of symbols constructs the meaning of signified[14].

- "And what strike the eyes here is the universal adaptability of this well-known melody, it can be used by political movement which are totally oppose to each other. It's never just meaning. It always has to also work as an empty container, open to all possible meanings. It's you know, that, you got feeling that we feel when we experience something pathetic and we say: oh my god, I'm so moved, there's something so deep... but you never know what this depth is, it void. This neutrality of frame. It's never as neutral as it appears"[15].

Zizek cites the fourth movement of Beethoven's Symphony No. 9 to illustrate the use of musical symbols in political campaigns. As audio-visual symbols, the chain of signifiers of music can be interpreted optionally, and a single symbol itself does not refer to any specific illusion and meaning. Otherwise, how can we explain the connotation of fascism and humanized communism in the same music? Specific to the 70th anniversary celebration itself is the same. It can be regarded as the emotional experience of the Imaginary as a complex interactive network of symbols. Different symbols can be randomly arranged and combined to produce completely different illusions and meanings, although these products share similar emotional experiences. As a neutral symbol close to the sensitive point of individual emotion, the event of veteran's tearful waving can be anchored in the connotation of nationalism, internationalism and even anti-war by different symbol networks. However, the construction of meaning is always a retrospective process: the perceptive symbols of veterans directly stimulate individual moving emotions, and are anchored by the illusion constructed by specific patriotic scene symbols, such as marching or waving party flags, to construct a bottom-up authentic patriotic emotion, and then change the value judgment of the activity itself. It might be that certain individuals were disgusted by the formalism, extravagance and semi-compulsory nature of the event, and were not interested in the PLA's formation and new weaponry. But they could not resist the neutral and simple emotion inspired by the tearful waving of veterans, the portraits of premier Zhou Enlai and the empty cars represent heroes and martyrs. In the field of patriotism production, these emotions will inevitably be captured by the symbol web constructed by authority. The positive emotions of individuals for a single symbol will be overlaid with other symbols, changing people's overall attitude on the event and political stance.

\section{Summary and The Theoretical Model}

From the perspective of group evolution: as a group of negative solidarity, the cohesion of the formation at the early stage of military training period comes from coercive power and uncertain rewards and punishments mechanism. In this case, individual choices depend only on economic rationality which aims to maximize individual interests. In the evolution process of the military training period from early stage to later stage, the school and the military instructor corps, such authority shape the common emotions of the formation at the macro-organizational level with identity group construction and punitive justice respectively. At this point, the formation initially formed a common emotions and cultural environment, which acts as a cohesive force anchoring the individuals in the formation. The rehearsal space acts as a set of symbolic systems, which on the one hand directly stimulated the positive subjective experiences of the individuals with perceptual symbols and on the other hand captured the heterogeneous individuals in a symbolic web constructed by the authority with specific neutral value symbols. At the same time, the psychological effects of the group within the social network and the functioning of the meaning universe made the constructed common feelings purer, and the formation formally evolves into a mechanical solidarity group sharing strong emotions and common values.

From the perspective of patriotism education, the construction of group identity mentioned above is in essence a low-level appropriation of the existing official patriotism. Under the background of home-country isomorphism, the state activates people's strong loyalty and vivid attachment to the concept of family through projection and association of the "Integrated Concept of Country". It also means that family identity and any identity group with a national interest can in turn appropriate this homogenous attachment. The situational definition of activist gives patriotic behavior and attitude a positive social meaning at the value orientation level. 
Although such social meaning is not a spontaneous emotional attitude, it provides an ideal place for the production of patriotic values later. The rehearsal scene weaved a web of meanings through different perceptive symbols, so that the individuals in it were anchored within the meaning with patriotism as the core, and then experienced a simple patriotic emotion from an authentic perspective. In this sense, It can be defined the rehearsal scene as a powerful patriotic production machine. To sum up, the celebration of the 70th anniversary is a set of patriotic education with a clear division of work. The activities in the later period of military training can be regarded as retrospective and utilitarian application of patriotism emotion, aiming to fix the participants in the formation. The rehearsal period, on the other hand, carries out patriotic indoctrination in an emotional and situational manner. Such indoctrination is so extensive and effective that it can even change the attitude of individuals who have a negative attitude towards the activity itself for a long time. In terms of the general practice of patriotism education, It can be also refer to the operation mode of retrospection and reproduction: in the retrospection stage, attention should be paid to the construction of identity groups and situations, while in the reproduction stage, the construction of the perceptive symbols network should be much account of.

\section{References}

[1] Emile Durkheim, The Division of Labor in Society, SDX Joint Publishing Company, Beijing, 2000: 81.

[2] Emile Durkheim, The Division of Labor in Society, SDX Joint Publishing Company, Beijing, 2000:68.

[3] James C. Scott, Weapons of the Weak, Yilin Press, Beijing, 2011: 341 .

[4] Graham Ward, The Certeau Reader, Blackwell Publishers, Oxford, 2000: 105.

[5] Slavoj Zizek, Welcome to the Desert of the Real, Yilin Press, Beijing, 2015: 17.

[6] Martha C. Nussbaum, For Love of Country: Debating the Limits of Patriotism, Beacon Press, Boston, 1996: 9.

[7] Emile Durkheim, The Division of Labor in Society, SDX Joint Publishing Company, Beijing, 2000: 70.

[8] Erving Goffman, The Presentation of Self in Everyday Life, Zhejiang People's Publishing House, Zhejiang, 1989.

[9] Wang Sibin, Introduction to Sociology, Peking University Press, Beijing, 2016.

[10] Zhao Wanli, Li Lubin, "Situational Knowledge and Social Interaction," Studies in Philosophy of Science and Technology, XXVI (05), pp. 87-93, 2009.

[11] Wang Liping, "The Significance of Group Psychology in Contemporary Political Analysis", Journal of Beijing Administrative College, (06), pp. 31-35, 2015.

[12] Slavoj Zizek, "Examined Life: Philosophy is in the Streets", youtube.com, May. 6, 2015.[Online]. Available: https://www.youtube.com/watch?v=j_K_79021hk.[Acc essed: Jan. 28, 2022].

[13] Tony Myers, Slavoj Zizek, Chongqing University Press, Chongqing, 2014: 32.

[14] Tony Myers, Slavoj Zizek, Chongqing University Press, Chongqing, 2014: 30.

[15] Slavoj Zizek, "Slavoj Zizek on Beethoven's 'Ode to Joy"”, youtube.com, Oct. 1, 2013.[Online]. Available:
https://www.youtube.com/watch?v=XM9erS90gTE.[Ac cessed: Jan. 28, 2022]. 